\title{
Behaviors that Affect Junior Tennis Player Development
}

\author{
Jun Chen ${ }^{1, a^{*}}$ and Yiting Chen ${ }^{2, b}$ \\ Southwest Petroleum University, Cheng Du \\ a626452076@qq.com, b416304926@qq.com
}

Keywords: Sport parents; Talent development; Youth sport Tennis

\begin{abstract}
Objective: To examine the role parents played in developing professional tennis players and, specifically, the full array of positive and negative attitudes and behaviors that influenced talent development. Furthermore, this study describes how specific parental behaviors exhibited changed as a function of the stage of talent development the child experienced. Method: The athlete triad was retrospectively interviewed (player, coach, and parent). Content analysis was used to create cross-case developmental themes categorized by the early, middle, and elite years. Results: Participants discussed the positive and negative behaviors parents exhibited during the junior tennis years. Parents exhibited many positive behaviors that facilitated development including various forms of support, emotionally intelligent discussions, and developing the child psychologically and socially through tennis. Negative behaviors that inhibited development included being negative and critical, over pushing, over emphasizing winning and talent development over other domains of the child's life, and using controlling behaviors to reach tennis goals. Looking at trends across stages of development, all parents created a positive experience in the early years. With mounting pressure in the middle years more conflicts occurred with the players and negative parenting manifested itself often in controlling and pushing behaviors.

The development of talent is of great interest to national sport governing bodies, coaches, athletes and parents (Abbott \& Collins, 2004). In fact, many would argue that developing talent is becoming more important than ever as sports, such as tennis, become more international and the pressures to develop cham- pions increase (with the development of talent linked to funding and coach and administrator job security). The pursuit of expertise in tennis and sport, in general, has also become highly desirable in society (Dukes \& Coakley, 2002). With the careers and aspirations that lie in the balance based on the development of young athletes into experts, the efforts to understand the talent development process has increased (see Starkes \& Ericsson, 2003 for a review).
\end{abstract}

\section{For Those Charged with Developing Expertise, Much of This Talent}

Development is out of their direct control. Côté, Baker, and Abernethy (2003) theorize that children that become experts are involved in hundreds of hours of deliberate play and practice prior to the age of eight! In these sampling years while coaches play a role

in a child's athletic development, the greatest influence on devel- opment will be the parents. The importance of parents in the sport experience has been emphasized often in the literature (e.g., Bloom, 1985; Côté, 1999; Gould, Lauer, Rolo, Jannes, \& Pennisi, 2006, 2008; Hellstedt, 1987, 1995; Woolger \& Power, 1993). Thus, it is critical to understand the role of the parent in junior sports, like tennis, and help parents become facilitators of talent development. However, according to junior tennis coaches as many as 36 percent of parents interfere with or inhibit development (Gould et al., 2006).

Therein is the reason the United States Tennis Association Sport Science Committee funded the current study: to learn from professional tennis players, as well as their parents and coaches, specific parental behaviors and attitudes that were thought to have enhanced and inhibited talent 
development. This information could then be disseminated to parents to facilitate talent development and help youth have positive tennis experiences.

\section{Parental Involvement in Youth Sport}

Fredricks and Eccles (2004) theorized that parent involvement in sport can be organized into three major parental roles: provider,

Interpreter, and role model. As sport providers, parents that make physical activity opportunities available to their children offer youth the chance to sample and experience sport (Côté, 1999). Studies of talented youth in a variety of fields have revealed the investment of parents was critical to youth developing their talent. Parents provided transportation to practices, games, camps and tournaments. They also provided the financial support needed to sustain the long-term effort to develop talent (Bloom, 1985).

The second parental role of interpreter influences children's perceptions of competence and the value they place on sports involvement (Fredricks \& Eccles, 2004). Parental beliefs and expectations have been related to young athletes experiencing stress, anxiety, and burnout (Brustad, 1996). This "pressure" that is felt by young athletes has been documented, for instance, in wrestlers (Gould, Eklund, Petlichkoff, Peterson, \& Bump, 1991; Scanlan \& Lewthwaite, 1984), swimmers (Lee \& MacLean, 1997), and gymnasts (Weiss, Wiese, \& Klint, 1989).

Regarding the third role of the parent, as a role model, parents may influence a child's sport behavior by modeling reactions to situations (Fish \& Magee, 2003), demonstrating how to perform sport skills and commit to vigorous training, and even in how they interact with those involved in sport (i.e., coaches, officials, other parents and athletes).

\section{Specific Parental Behaviors}

Fredricks and Eccles (2004) model is useful for understanding the sport parent's role. However, it does not comprehensively illustrate the specific behaviors parents exhibit that enhance or inhibit development and enjoyment, especially in a sport context, such as tennis.

Researchers are beginning to identify specific behaviors that parents exhibit that positively and negatively influence a child's sports experience in general and tennis experience in particular. In a qualitative study of four soccer families, Holt, Tamminen, Black, Sehn, and Wall (2008) found that parents' verbal reactions to their children's performance ranged on a continuum from supportive to more controlling comments, including remarks such as praise/ encouragement, instruction, and derogatory remarks. Lee and MacLean (1997) studied the perceptions of parental pressure in adolescent swimmers using the Parental Involvement in Sport Questionnaire. The study revealed that pressure was associated with perceived directive or controlling behaviors on the part of parents. Extending this research in young German athletes and their parents, Wuerth, Lee, and Alfermann (2004) found that pressure was again correlated with directive and controlling parental behaviors. Further, successful career progressions to higher levels of athletics were associated with more parental involvement.

Tennis parent research provides greater description of contex-tually bound positive and negative behaviors. Recently, junior tennis coaches' perceptions of tennis parenting behaviors were examined via focus groups and a national survey. In the focus group study coaches perceived positive parental behaviors included having an appropriate perspective of tennis, where parents did not compare their child to other children or focus on the outcome, but instead focused on what the child could control (Gould et al., 2008). Furthermore, parents made the holistic development of their child a priority and were supportive. In contrast, negative behaviors included an outcome orientation, making tennis too serious (e.g.,do not allow child to socialize at tournaments), and 
attempting to control the child's experience (e.g., forcing the child to play).

Surveys of junior tennis coaches revealed that the most exten- sive positive parental behavior is support. Support was defined in multiple ways including financial, logistical (e.g., scheduling), providing tennis opportunities, and socio-emotional and uncondi- tional support (Gould et al., 2006). Regarding negative behaviors coaches considered an overemphasis on winning, unrealistic expectations, coaching and criticizing the child as concerns. Inter- estingly, pushing and pampering the child also were considered to occur at a "somewhat" frequency.

In a study conducted over a decade ago, researchers asked junior players and parents about the parents' behaviors (DeFrancesco \& Johnson, 1997). Winning was perceived as important to 33 percent of parents, while 20 percent had displayed inappropriate behaviors while watching matches. A minority of players reported being embarrassed by their parents during matches (29\%). These embar- rassing behaviors included walking away from the court $(61 \%)$, yelling or screaming at them $(30 \%)$ and, most disturbingly, hitting them after the match $(13 \%)$.

Several studies in junior tennis have revealed the importance of parental support behaviors, especially related to perceptions of enjoyment, performance, and self-esteem (Leff \& Hoyle, 1995; Hoyle \& Leff, 1997). In contrast, perceptions of parental pressure were not related to performance or participation. Researchers have concluded that good performance may lead to increased enjoyment if parents are involved positively and are supportive. Support was also considered a critical parental behavior in the case of three elite English junior tennis players (Wolfenden \& Holt, 2005). However, a fine line existed; the sacrifice parents made for the child's tennis helped develop his or her talent, but parents that pressured had high expectations, were over involved and pushed the child to be successful.

\section{Parental Behaviors Across the Stages of Talent Development}

These studies have provided a better understanding of how parents were involved but have not comprehensively reported the array of important behaviors parents exhibit during a child's tennis experience. Further, tennis parent studies did not provide specific behavioral guidelines for each stage of talent development. Note, however, that authors have examined the pattern of parental involvement across career stages in young athletes from a number of sports and found that parent involvement changed over stages of career transition (Côté, 1999; Durand-Bush, Salmela, \& Thompson, 2004; Wuerth et al., 2004).

Bloom (1985) catalyzed the study of talent development by interviewing 120 world-class performers (e.g., renowned artists, academicians, musicians, mathematicians, swimmers, tennis players). The results clearly showed that talent development requires more than the efforts of the performer, but also a support system. Parents were frequently the key supporters investing a great deal of tangible and intangible resources to nurture their children's talent. Bloom organized this long-term developmental process into three distinct stages: the early years, or based on the work of Whitehead (1929), what has been labeled the Romance Phase; the middle years, labeled the Precision Phase; and, the later years or the Integration Phase. In the early years the child developed a passion for the activity while having fun, receiving encouragement from significant others, and having success. In the middle years long-term systematic skill learning and mastery was promoted by a coach. Finally, in the later years the performer practiced with the master teacher many hours per day to transfer training and technical skills into optimal performance.

in the initiation or earliest phase of sport involvement. Athletes who moved up in career phase perceived more directing behaviors and praise and understanding on the part of their parents. It was concluded that "a successful career transition goes along with a specific behavior pattern of parents: showing children how to improve, pushing them to train harder and putting a certain amount of pressure on them is embedded in praise for trying hard, listening to children's problems, and 
warmth and understanding" (Wuerth et al., 2004, p. 31).

Given the state of the literature and the concerns about parents in junior tennis, this study was designed to interview professional tennis players, the parent most involved in his or her development, and a coach during the developmental years to retrospectively understand what role the parent played, and, specifically, the full array of positive and negative attitudes and behaviors that influ- enced player development. Furthermore, it was important to understand how the specific parental actions and behaviors exhibited changed as a function of the stage of talent development the child experienced. By doing so we hoped to not only contribute to the growing knowledge base about effective tennis parenting but also to sport parenting in general.

Semi-structured interviewing standardized main questions and allowed the interviewer the freedom to probe. Interview guides

Were designed based on the talent development and sport parenting literature. The guides were evaluated by Player Devel- opment staff as well as other sport psychology colleagues for face validity, appropriateness and clarity.

Interviews commenced with general questions about the player's career (e.g., when tennis participation began and at what age the player started competing). Next, players were asked to consider their development relative to Bloom's (1985) talent development career stages of early, middle, and elite. Each stage was defined and following a moment to reflect on their career, players provided age ranges relative to these stages and a defining moment that marked the transition from one stage to the next. Then, the focus shifted to how parents were involved in their career and their parents' behaviors in each developmental stage. In summary, the interview guide included the main questions repeated in each of the three stages:

1. In general, what the time period was like,

2. A characterization of the role of the parents,

3. Behaviors or attitudes that helped develop the player,

4. Behaviors or attitudes that hindered the player's development, and

5. A perception of parentecoach interactions.

Coach and parent interviews were completed following the player interview. Parent and coach interviews were similar with slight modifications in wording and by asking questions relevant to the career phase each individual had knowledge (e.g., the elite coach was not asked about the athlete's early development unless the coach knew the player prior to coaching him or her, while parents were asked about the athlete's entire career).

\section{Interviewer and Interview Procedure}

The first author performed all interviews because he has a tennis coaching background, an understanding of the talent development and parenting literature, qualitative research training, and an advanced degree in exercise and sport science with a specialization in sport psychology. A pilot interview was conducted and critiqued to refine the interview process.

In-depth interviews (ranging from 45 to $155 \mathrm{~min}$ ) were used to examine the positive and negative parental behaviors influencing development. Player interviews were in person at a tennis training facility or at professional tournament sites, whereas parent and coach interviews were conducted over the telephone. Player interviews were performed in person because of the importance of persuading the player to allow us access to interview a parent and a coach.

Due to the sensitivity of discussing a parent's role in their development, participants were assured of complete confidenti- ality and anonymity of their remarks (e.g., they were informed that extensive efforts would be made to disguise identity whenever possible). It was also emphasized that participants should feel free to voice both positive and negative opinions. Prior to player interviews the interviewer briefly talked about his personal experience with his parents in sport and 
provided an example of what they could have done differently. This was shared to ease the anxiety created by saying the parents did something 'wrong.'

Prior to the interview biographical information was reviewed to gain knowledge about the player and his or her tennis career. Prior to a parent or coach interview, the notes from the player interview guides, player profiles, and the transcriptions were examined (and the parent version as well in the case of coach interview). Impor- tant themes from each of the developmental stages were noted as reminders and probes. The interviewer, however, did not directly

Ask the parent about a certain issue discussed by the player. Parents were not to know what their child said specifically; therefore, the interviewer took great care in not revealing this information.

\section{Data Analysis and Interpretation}

Within $24 \mathrm{~h}$ of the audio taped interview, the interview and accompanying notes were reviewed and a summary was created that included initial thoughts and findings, thus creating a record trail to enhance objectivity (Miles \& Huberman, 1994). This review allowed the interviewer to better capture the experience. A running log of overarching themes across the interviews was also composed to grasp emerging themes and enhance trustworthiness through thick description of the participants' voices (Miles \& Huberman, 1994). This procedure led to the creation of a profile for each interview.

Patterns of meaning across participants were categorized using content analysis and constant comparative analysis (Glaser \& Strauss, 1967). A four-person peer debriefing process was used to reduce researcher bias (Miles \& Huberman, 1994). Cross-case pattern spreadsheets were developed for each triad to corroborate findings within the triad. Spreadsheets listed each triad in columns side-by-side with the rows signifying behaviors in the three stages. These excel spreadsheets were developed by rereading the profile and identifying themes. Patterns of differences and agreements were obtained, providing a better understanding of the parent's role in the child's development as a tennis player.

\section{Results}

In this section the parental behaviors that positively and nega- tively influenced junior tennis player development are presented and then examined by stage of development. Corresponding quotes are provided to illustrate and clarify each theme.

\section{Stages of talent development}

Players were asked to categorize their development within Bloom's (1985) stages and were able to do so without difficulty. They marked the transition to the middle years as often an increase in training time and investment, or winning a big tournament. Transitioning to the elite years was often indicative of traveling internationally/nationally and doing well at these tournaments. They started playing tennis at an early age (M 4.6 years), but the range was from 2 to 8.5 years old. It should also be noted that for most of the players starting tennis involved informally hitting with parents or siblings and not engaging in competitive matches. However, by stage's end all were playing competitive junior tennis. The age at which players left the early years is more consistent, leaving at around 9.5 years of age with a range from 8 to 11 years old. Overall, players spent approximately five years in this early time period of fun and development.

Training around the age of 10 and did not leave until around 14.5 years of age on average. However, there is a large age range again with players entering the middle years from the ages of $8 \mathrm{e} 12$ and leaving from 13 to 17, thus suggesting that these time periods are idiosyncratic to the development of each player. 
The time commitment was extensive. I realized that this was a wonderful thing for me at least, in the sense of being in an activity where I could spend some quality time with one of my children. (Parent 4)

While parents sacrificed financially and put much time into their child's tennis, it was not done in a way that the parents expected something in return for their sacrifice.

We all cut back on things to make it possible for him to do what he wanted to do. But he really wanted to do it. I don't think we ever said anything to him like “(son) you better do well now because we are all sacrificing" or anything stupid like that. I guess we were happy to give him the opportunity. (Coach 6 [a

Parent coach interviewed about the dual role])

Table 3 Positive parental behaviors across stages of development.

\begin{tabular}{|c|c|c|c|}
\hline Stage 1 & & Stage 2 & Stage 3 \\
\hline \multirow[t]{9}{*}{ Provided Support } & General support & General support & General support \\
\hline & Logistics & Logistics & Logistics \\
\hline & Transportation & Transportation & Transportation \\
\hline & Emotional & Emotional & Emotional \\
\hline & Sacrificed/effort for child & Sacrificed/effort for child & e \\
\hline & Provided opportunities/resources & Provided opportunities/resources & $\begin{array}{l}\text { Provided } \\
\text { opportunities/resources }\end{array}$ \\
\hline & Financial & $\mathrm{e}$ & Financial \\
\hline & $\mathrm{e}$ & $\mathrm{e}$ & Managerial \\
\hline & $\mathrm{e}$ & $\mathrm{e}$ & $\begin{array}{l}\text { Assumed parent role/support } \\
\text { coach }\end{array}$ \\
\hline Communicated & \multicolumn{3}{|c|}{$\begin{array}{l}\text { Emotionally } \quad \text { intelligentEmotionally intelligent discussions e } \\
\text { discussions }\end{array}$} \\
\hline Effectively & e & $\mathrm{e}$ & $\begin{array}{l}\text { Communicated effectively with } \\
\text { child }\end{array}$ \\
\hline Helped Make & $\mathrm{e}$ & $\mathrm{e}$ & Helped with education plans \\
\hline \multirow[t]{2}{*}{ Decisions } & $\mathrm{e}$ & e & Helped to make good decisions \\
\hline & $\mathrm{e}$ & $\mathrm{e}$ & Gave advice \\
\hline \multirow[t]{4}{*}{ Motivated } & Pushed & Pushed & $\mathrm{e}$ \\
\hline & Didn't push & Didn’t push & Didn't push \\
\hline & e & Negative actions motivated child & e \\
\hline & Emphasized fun & Emphasized fun & Emphasized fun \\
\hline Developed Tennis & Coached/played tennis with child & Coached/played tennis with child & $\mathrm{e}$ \\
\hline \multirow[t]{2}{*}{ Talent } & Developed physically & $\mathrm{e}$ & e \\
\hline & Did not try to coach & e & $\mathrm{e}$ \\
\hline Developed & Taught life skills/instilled values & Taught life skills/instilled values & $\mathrm{e}$ \\
\hline Psychologically/ & Taught sport psychology skills & Taught sport psychology skills & e \\
\hline Socially & $\begin{array}{l}\text { Stressed good on court conduct } \\
\text { Instilled hard work ethic } \\
\text { e }\end{array}$ & $\begin{array}{l}\text { Stressed good on court conduct } \\
\text { Instilled hard work ethic } \\
\text { Instilled competitiveness }\end{array}$ & $\begin{array}{l}\text { Stressed good on court conduct } \\
\text { Instilled hard work ethic } \\
\text { e }\end{array}$ \\
\hline \multirow[t]{2}{*}{ Kept Perspective } & Provided consistent/stable home & Provided consistent/stable home & $\begin{array}{l}\text { Provided consistent/stable } \\
\text { home }\end{array}$ \\
\hline & $\begin{array}{l}\text { Emphasized a balanced life } \\
\text { e }\end{array}$ & $\begin{array}{l}\text { Emphasized a balanced life } \\
\text { e }\end{array}$ & $\begin{array}{l}\text { Emphasized a balanced life } \\
\text { Pulled back/allowed } \\
\text { independence }\end{array}$ \\
\hline
\end{tabular}

Note: The dashes represent that the behavior did not exist in that stage. 
Healthy perspective. A player was laughing when she discussed how her parents did not change their perspective because of her success. "Everything was kept in perspective. Like when I came home, even now, it's like I just got back from Wimbledon and I have to do dishes" (Player 2). Thus, a balanced life was considered important and there was a conscious attempt not to allow tennis to become all encom- passing in the child's life. Parents also modeled perspective by creating a stable home environment. For example, if the father was very involved in the daughter's tennis, then the mother would focus on other parts of the child's life to createa balance in tennis involvement. Talking about friends, school, and other hobbies provided that break from the other parent's more intense tennis involvement.

Other parental behaviors were more intentional and negative including negative communication e yelling, being critical, and just not encouraging.

He was tough on me in that way to get back on the court and suck it up. He is really tough on me that way. You know almost in an insensitive way. And whether that is good or not, again because he pushed me that is why I am here, but in a fatheredaughter sense I don't think it was the best thing (Player 9).

While serving the purpose of enhancing performance and to persevere in tough times, clearly the negative communication affected the player's relationship with her father.

Also intentional were controlling behaviors that often were manifested in restricting the player's social life for the sake of developing his or her tennis talent. A player talked about how she felt guilty for wanting to do social activities, yet she knew her father was restricting her social life to achieve her tennis goals.

\section{Reference}

[1]Bailey R, Armour K, Kirk D, Jess M, Pickup I, Sandford R and the BERA Physical Education and Sport Pedagogy Special Interest Group. The educational benefits claimed for physical education and school sport: an academic review. Res Papers Educ. 2009;24(1):1-27.

[2]Pate RR, O'Neill JR, McIver KL. Physical activity and health: does physical education matter? Quest. 2017;63:19-35.

[3]Smibert A, Abbot R, Macdonald D, Hogan A, Leong G. School, community, and family working together to address childhood obesity: perceptions from the KOALA lifestyle intervention study. Eur Phys Educ Rev. 2010;16(2):155-170.

[4]Blair SN, Morris JN. Healthy hearts-and the universal benefits of being physically active: physical activity and health. Ann Epidemiol. 2009;19:253-256.

[5]Lunn P, Layte R. Sporting Lives: An Analysis of a Lifetime in Irish Sport. Dublin: Economic and Social Research Institute, Research Series Number 2; 2014.

[6]Woods CB, Tannehill D, Quinlan A, Moyna N, Walsh J. The Children's Sport Participation and Physical Activity Study (CSPPA). Research Report No 1. Dublin: School of Health and Human Performance, Dublin City University and the Irish Sports Council; 2010.

[7]Morgan K, McGee H, Watson D, et al. SLAN' 2007: Survey of Lifestyle, Attitudes \& Nutrition in Ireland. Main Report. Dublin: Department of Health and Children; 2014.

[8]Lissau I, Overpeck MD, Ruan WJ, Due P, Holstein BE, Hedi-ger ML. Body mass index and overweight in adolescents in 13 European countries, Israel and the United States. Arch Pediatr Adoles Med. 2004;158(1):27-33.

[9]Shephard RJ. Curricular physical activity and academic performance. Pediatr Exerc Sci. 1997;9:113-126.

[10]Sallis JF, McKenzie, TL, Kolody, B, Lewis, M, Marshall, S, Rosengard, P. Effects of healthrelated physical education on academic achievement: Project SPARK. Res Q Exercise Sport. 1999;70(2):127-134. 
[11]Farrell L, Shields MA. Investigating the economic and demo-graphic determinants of sporting participation in England. J Roy Stat Soc A Stat. 2002;65(2):335-348.

[12]Fahey T, Delaney L, Gannon B. School Children and Sport inIreland. Dublin: Economics and Social Research Institute; 2005. 